\title{
Roll with the fear: environment and state dependence of pill bug (Armadillidium vulgare) personalities
}

\author{
Gergely Horváth ${ }^{1}$ (D) - László Zsolt Garamszegi ${ }^{1,2,3}$ • Judit Bereczki ${ }^{4}$ Tamás János Urszán ${ }^{1} \cdot$ Gergely Balázs ${ }^{1}$. \\ Gábor Herczeg ${ }^{1}$
}

Received: 8 November 2018 / Revised: 23 January 2019 / Accepted: 24 January 2019 /Published online: 7 February 2019

(C) The Author(s) 2019

\begin{abstract}
Most studies on animal personality evaluate individual mean behaviour to describe individual behavioural strategy, while often neglecting behavioural variability on the within-individual level. However, within-individual behavioural plasticity (variation induced by environment) and within-individual residual variation (regulatory behavioural precision) are recognized as biologically valid components of individual behaviour, but the evolutionary ecology of these components is still less understood. Here, we tested whether behaviour of common pill bugs (Armadillidium vulgare) differs on the among- and within-individual level and whether it is affected by various individual specific state-related traits (sex, size and Wolbachia infection). To this aim, we assayed risk-taking in familiar vs. unfamiliar environments 30 times along 38 days and applied double modelling statistical technique to handle the complex hierarchical structure for both individual-specific trait means and variances. We found that there are significant among-individual differences not only in mean risk-taking behaviour but also in environment- and time-induced behavioural plasticity and residual variation. Wolbachia-infected individuals took less risk than healthy conspecifics; in addition, individuals became more risk-averse with time. Residual variation decreased with time, and individuals expressed higher residual variation in the unfamiliar environment. Further, sensitization was stronger in females and in larger individuals in general. Our results suggest that among-individual variation, behavioural plasticity and residual variation are all (i) biologically relevant components of an individual's behavioural strategy and (ii) responsive to changes in environment or labile state variables. We propose pill bugs as promising models for personality research due to the relative ease of getting repeated behavioural measurements.
\end{abstract}

Keywords Animal personality $\cdot$ Behavioural plasticity $\cdot$ Residual variation $\cdot$ Individual state $\cdot$ Environmental differences . Wolbachia

\section{Introduction}

Behaviour is one of the most flexible traits of animals (WestEberhard 2003), yet some level of repeatability in behaviour across time and ecological situations (i.e. animal personality) exists (Bell et al. 2009; Garamszegi et al. 2012). Intuitively,

Communicated by: Rumyana Jeleva

Electronic supplementary material The online version of this article (https://doi.org/10.1007/s00114-019-1602-4) contains supplementary material, which is available to authorized users.

Gergely Horváth

gergohorvath@caesar.elte.hu

Extended author information available on the last page of the article the presence of non-random among-individual behavioural variation should constrain behavioural plasticity (Niemelä et al. 2013). This is true to a certain extent, but individuals still preserve the ability to alter their behaviour in response to changing environment, while their behaviour relative to each other remains different (Biro et al. 2010; Dingemanse et al. 2010; Briffa et al. 2013; Mathot and Dingemanse 2014). Further, it seems that in addition to non-random variation in mean behaviour, individuals can also show variation in their reaction to environmental change (within-individual behavioural plasticity) (Dingemanse et al. 2010; Westneat et al. 2011; Dingemanse and Wolf 2013; Mitchell and Biro 2017). Finally, biological validity and importance of withinindividual behavioural variation not induced by environmental change, or in other words, the 'rigidity' of an individual's behaviour type in a certain environment (within-individual residual variation), were recognized recently (Stamps et al. 
2012; Biro and Adriaenssens 2013; Briffa 2013; Briffa et al. 2013). Hence, within-individual behavioural plasticity (hereafter: behavioural plasticity) and within-individual residual variation (hereafter: residual variation) should be considered as potentially independent components of individual behavioural strategy (Dingemanse et al. 2010; Kralj-Fišer and Schneider 2012; Briffa 2013; Dingemanse and Wolf 2013; Westneat et al. 2013, 2015; Mitchell et al. 2016). However, background mechanisms affecting emergence of individual variation in behavioural plasticity and residual variation are less understood. In addition, it is still not entirely clear whether these components can evolve independently or individual differences in within-individual behavioural variation are related to personality (Niemelä et al. 2013; Mathot and Dingemanse 2014; Stamps 2016).

Recently, a growing body of studies suggests that even short-term variation in ecological conditions and inherently labile state-linked traits could create stable differences in behavioural strategies (DiRienzo et al. 2016; Lichtenstein et al. 2016; Horváth et al. 2017). Parasites are among the most important environmental factors known to create stable behavioural differences (Barber and Dingemanse 2010; Kortet et al. 2010; Poulin 2013). Direct or indirect negative effects of infections (e.g. low body condition) may result in differences in individual state, which may eventuate the emergence of individual behavioural strategies in order to cope with these disadvantages (DiRienzo et al. 2015, 2016; Horváth et al. 2016). In arthropods, Wolbachia are important parasitic bacteria (Hilgenboecker et al. 2008; Werren et al. 2008) with remarkable effects on hosts' physiology, including parthenogenesis, reproductive incompatibility, feminization and male killing (see Werren and Windsor 2000; Werren et al. 2008; Le Clec'h et al. 2012, 2013). Although behavioural impact of Wolbachia is less documented, it seems that infection generally affects mating behaviour of males (see Ming et al. 2015; Moreau et al. 2001; Vala et al. 2004; Zhao et al. 2013). Also, in a parasitic wasp (Leptipolinia heterotoma), it was found that Wolbachia reduces locomotor activity of both sexes (Fleury et al. 2000). Generally speaking, Wolbachia is expected either to decrease behavioural activity by impairing physiological performance of the hosts or to increase it by host manipulation or inducing some sort of terminal investment (Sicard et al. 2010; Chevalier et al. 2011).

Conglobation is a special type of tonic immobility and is a common defensive behaviour for various arthropod taxa (Tuf et al. 2015). Conglobation can be used as a proxy of risktaking behaviour (Carter et al. 2012; Beckmann and Biro 2013). Species of pill bugs (family: Armadillidiidae, order: Isopoda, subphylum: Crustacea) are capable to roll their body into an uninterrupted sphere, hiding their vulnerable posterior appendages (uropods), legs and antennae. Conglobation protects common pill bug (Armadillidium vulgare) from most invertebrate and small-sized vertebrate predators, while larger vertebrate predators easily overlook small, immobile prey (Matsuno and Moriyama 2012; Tuf et al. 2015). Considering how easy it is to measure conglobation time, pill bugs might be excellent models for animal personality research, where the current statistical approaches are data hungry and the necessary number of within-individual repeated measures is challenging to reach with most species (Garamszegi and Herczeg 2012).

In the present paper, we studied risk-taking of adult A. vulgare by performing 30 repeated behavioural assays in two different environments (familiar vs. unfamiliar). We studied the effects of environment and various state variables (Wolbachia infection, body size, sex) on individual behaviour on different levels. First, we were interested whether individuals differed in mean risk-taking (i.e. among-individual variation), in their reaction norms (i.e. behavioural plasticity) and residual variation. Second, we tested whether these components are affected by environment and individual state. We expected lower risk-taking in the unfamiliar environment. We had no prediction regarding the effects of sex or size. Regarding residual variation, theory predicts increased within-individual variability under predation risk (Hugie 2003) as prey animals may reduce the probability of capture by predators by displaying unpredictable behaviour (Humphries and Driver 1970; Jones et al. 2011). However, empirical data are somewhat contradictory (see Briffa 2013; Velasque and Briffa 2016; Urszán et al. 2018). Displaying the highest residual variation may not be the best antipredator strategy; also, level of behavioural rigidity may depend on prevailing environmental conditions (Richardson et al. 2018), but more importantly, on development (see Bierbach et al. 2017). Thus, although we did not form a directional hypotheses regarding how different environments would affect residual variation of risk-taking in pill bugs, we expect that the level of residual variation indeed differs between familiar vs. unfamiliar environments. Further, we expected both environmentally induced plasticity in the form of lower risk-taking in the unfamiliar, potentially dangerous environment and plasticity along time in the form of habituation to the laboratory conditions. The latter was expected to be stronger in the unfamiliar environment.

\section{Methods}

\section{Study animals}

We collected $60 \mathrm{~A}$. vulgare individuals ( 26 males, 33 females, 1 N/A [damaged specimen]) on 9 May 2014 in the Kamaraerdő, Budapest (47² 26' 19.90" N, $18^{\circ} 58^{\prime} 52.57^{\prime \prime}$ E). During May, this oakwood forest is characterized by a 
relatively dense vegetation and high cover of leaf litter. We searched for animals under leaves and decaying wood at different sites. Only one individual was collected at a certain spot, and at least $50 \mathrm{~m}$ was left between spots in order to reduce the chance of sampling individuals from the same family. Individuals were transported to the facilities of Eötvös Loránd University, where they were housed individually in white opaque plastic boxes $(15.5 \mathrm{~cm} \times 11 \mathrm{~cm} \times 12 \mathrm{~cm}$, length, width, height, respectively) with a 1-cm-deep substrate consisting of mixture of coconut fibre and soil. Humidity was maintained by spraying the substrate with distilled water twice a day, and fresh carrot was provided as food weekly. The experimental animals have always eaten from the food, but never fully consumed it; hence, the experimental animals were fed ad libitum. We provided 12-h light period per day during the experiment. Dim light was provided by Repti Glo 2.0 Full Spectrum Terrarium Lamps (Exo Terra, Rolf V. Hagen Inc., Holm, Germany), which do not emit considerable heat but mimics the full spectrum natural light. At the end of the experiment, we sexed the individuals and measured the body size (diameter of conglobated individuals; to the nearest $0.01 \mathrm{~mm}$ ) and specimens were conserved in $96 \%$ ethanol for Wolbachia screening (see below). All individuals were screened for Wolbachia (see Supplementary Material for details).

\section{Behavioural assays}

Individual behaviour was evaluated 30 times during 38 days between 12 May and 19 June. Days without measurements were distributed randomly. Each individual's behaviour was evaluated in two different environments (familiar vs. unfamiliar) daily, resulting in 60 repeats per individual. Behavioural assays were carried out between 9.00 and 12.00 a.m. (UTC + 02.00), and 1-h break was provided between the two assays. The order of individuals within and between environments was randomized daily.

Risk-taking was estimated by latency to restart activity (time spent immobile in conglobation) after a simulated predator attack. Animals were removed from their home boxes, after which the experimenter gently squeezed the animal to trigger conglobation, then dropped it to the surface depending on treatment from a standard $(10 \mathrm{~cm})$ height. This treatment is similar to manipulation by larger vertebrate predators (e.g. birds and lizards) (see Tuf et al. 2015). In the familiar environment treatment, individuals were elevated from and dropped back to their home boxes, while in the unfamiliar environment treatment, individuals were dropped to a white plastic sheet illuminated directly (with $40 \times$ G4 Halogen Light Bulb, $10 \mathrm{~W}, 12 \mathrm{~V}$ ). Animals were considered to restart activity when they fully stretched their body and started to move their legs in an attempt to escape. If an individual did not restart activity in $15 \mathrm{~min}$, the assay was stopped and the individual was assigned maximum score (900 s). This happened only in seven cases, including four individuals; hence, we used the maximum score in the subsequent analyses. For unknown reasons, more than half of the collected individuals died soon after being transported to the laboratory and one individual had to be removed from the analyses because of its extremely outlying size. Thus, we used data (60 risk-taking measurements) from 25 individuals, 11 males and 14 females.

\section{Statistical analysis}

Latency data were log-transformed to achieve normal distribution of model residuals. To be able to fit reaction norms, environment was treated as a continuous measure by assigning -1 to the 'familiar' situation and 1 to the 'unfamiliar.' Continuous variables were centred for the analyses by bringing them to scale with a zero mean and unit variance. Dummy variables were created for the categorical variables to use them in the Bayesian modelling (see below). To describe the hierarchically structured behavioural data, we relied on a framework based on linear mixed modelling (LMMs) according to the following equation:

$$
\begin{aligned}
\log \left(Y_{i j k}\right)= & \left(\beta_{0}+\operatorname{ind}_{0 i}+\operatorname{day}_{0 j}\right)+\left(\beta_{1}+\operatorname{ind}_{1 i}\right) x_{1 i j k} \\
& +\left(\beta_{2}+i n d_{2 i}\right) x_{2 i j k}+\beta_{3} x_{3 i}+\beta_{4} x_{4 i}+\beta_{5} x_{5 i} \\
& +\beta_{6} x_{6 k}+\varepsilon_{i j k}
\end{aligned}
$$

where $Y_{i j k}$ is the latency for individual $i$ measured in day $j$ and at the $k$ th observation within a day, $\beta_{0}$ is the population mean latency, $\beta_{1}-\beta_{6}$ are the mean level parameters that describe the effect of covariates $x_{1}-x_{6}$ (environment, day, sex, size, infection status and order within a day, respectively), ind $d_{0 i}$ is the random effect term capturing the deviation of individual $i$ from the population mean, while $d a y_{0 j}$ is the random effect term depicting the deviation caused by day-specific effects. The model also considers random slopes ind $d_{1 i}$ and ${ }_{i n d} d_{2 i}$ to deal with among-individual differences in plasticity with respect to novel environment and with respect to day (habituation), respectively. The model requires the following assumptions:

$$
\begin{aligned}
& \operatorname{ind}_{0 i} \sim N\left(0, \sigma_{\text {ind }_{0}}^{2}\right) \\
& \operatorname{day}_{0 j} \sim N\left(0, \sigma_{\text {day }_{0}}^{2}\right) \\
& \text { ind }_{1 i} \sim N\left(0, \sigma_{i n d_{1}}^{2}\right) \\
& \operatorname{ind}_{2 i} \sim N\left(0, \sigma_{i n d_{2}}^{2}\right) \\
& \varepsilon_{i j k} \sim N\left(0, \sigma_{r e s}^{2}\right)
\end{aligned}
$$


Accordingly, the random terms are assumed to be normally distributed with a mean of zero and a respective variance, i.e. $\sigma_{\text {ind }}^{2}$ (among-individual variance in mean latency), $\sigma_{d a y_{0}}^{2}$ (among-day variance in mean latency), $\sigma_{i n d_{1}}^{2}$ (among-individual variance in plasticity) and $\sigma_{i n d_{2}}^{2}$ (among-individual variance in habituation). The error term is assumed to rely on a common residual variance $\sigma_{r e s}^{2}$ (within-individual variance).

We defined the above starting model based on a list of considerations. First, all of the fixed predictors are biologically relevant and can be hypothesized to affect the focal behavioural trait either at the among-individual or at the within-individual level. Second, the random effects were chosen to describe the hierarchical structure of the data arising from the design of the study, as well as to accommodate our main predictions concerning individual differences in plasticity and habituation. Accordingly, with this model, we could test whether (i) risk-taking behaviour was linked to individual characteristics like sex, size or health status and whether (ii) environment- or timeinduced (i.e. habituation) behavioural plasticity was present. For simplicity and to avoid too many parameters to be estimated, we did not define interaction terms among the fixed predictors. Similarly, we have not considered covariance between random slopes and intercepts. To verify that the random part of the above model is appropriate for further evaluation, we defined alternative models in the lme4 R package (Bates et al. 2015) and examined their goodness of fit relative to the model described in Eq. (1) by using likelihood ratio test. These investigations revealed that both random intercept terms are significant $\left(P<0.001\right.$ for both $i n d_{0 i}$ and $\left.d a y_{0 j}\right)$, that random intercept and slope models offer better fit to the data than the random intercept only models $\left(P=0.018\right.$ for $i n d_{1 i}$ and $P$ $<0.001$ for $i n d_{2 i}$ ) and that allowing correlation between random intercepts and slopes does not imply further improvement statistically $(P=0.052$ for the correlation between $i n d_{0 i}$ and $i n d_{1 i}, P=0.373$ for the correlation between ind $_{0 i}$ and ind $_{2 i}$ ).

Given Eq. (6), the above model assumes that residuals have a homogeneous variance, which is a strict assumption and does not accommodate a possibility for testing amongindividual differences in predictability, which corresponds to one of the main hypotheses of this study. To account for heterogeneous residual structure, we adopted an approach based on double hierarchical general linear models, which allows fitting the main and the dispersion parts of an LMM within the same statistical framework (Lee and Nelder 1996, 2006), with the latter capturing the essence of residual variation (Westneat et al. 2013; Cleasby et al. 2015; Mitchell and Biro 2017). Accordingly, we kept the above model and added another model for the standard deviation (SD) of risk taking, as follows. First, we assumed heterogeneous residual variance by replacing Eq. (6) with

$\varepsilon_{i j k} \sim N\left(0, \sigma_{y i j k}^{2}\right)$

which permits distinct residuals for each observation that can be further described as

$$
\begin{aligned}
\log \left(\sigma_{y j j k}\right)= & \left(\gamma_{0}+\text { ind }_{\sigma 0 i}+\text { day }_{\sigma 0 j}\right)+\gamma_{1} x_{1 i j k}+\gamma_{2} x_{2 i j k} \\
& +\gamma_{3} x_{3 i}+\gamma_{4} x_{4 i}+\gamma_{5} x_{5 i}+\gamma_{6} x_{6 k}
\end{aligned}
$$

In this equation, $\gamma_{0}$ is the mean log residual $\mathrm{SD}, \gamma_{1}-\gamma_{6}$ are parameters describing the effect of covariates (environment, day, sex, size, infection status and order within a day, respectively) on predictability. The random terms $i n d_{\sigma 0 i}$ and $d a y_{\sigma 0 j}$ reflect individual- and day-specific deviations, respectively, from the population-specific mean log SD. For these random terms, we assumed that

ind $_{\sigma 0 i} \sim N\left(0, \sigma_{\text {бind }}^{2}\right)$

$\operatorname{day}_{\sigma 0 j} \sim N\left(0, \sigma_{\sigma d a y}^{2}\right)$

yielding that different individuals and days can be characterized by different residual variation, and the among-individual and among-day variance of residual variation can be estimated

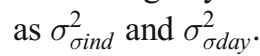

We were also interested in whether individual-specific behavioural plasticity and habituation can be linked to individual characteristics. To this end, we further extended the modelling framework by adding linear regressions that describe individual-specific plasticity and habituation. Therefore, we replaced Eqs. (4) and (5) with

$\operatorname{ind}_{1 i} \sim N\left(\right.$ plast $\left._{i}, \sigma_{\text {ind }_{1}}^{2}\right)$

$\operatorname{ind}_{2 i} \sim N\left(h a b_{i}, \sigma_{\text {ind }_{2}}^{2}\right)$

in which each individual can be described by a specific mean plasticity and habituation value depending on their individual characteristics as specified by

plast $_{i}=0+\delta_{1} x_{3 i}+\delta_{2} x_{4 i}+\delta_{3} x_{5 i}$

$h a b_{i}=0+\varphi_{1} x_{3 i}+\varphi_{2} x_{4 i}+\varphi_{3} x_{5 i}$

Here, $\delta_{1}-\delta_{3}$ and $\varphi_{1}-\varphi_{3}$ stand for parameters that link the main individual-specific attributes $\left(x_{3}-x_{5}\right.$, sex, size and infection status) to plasticity and habituation, respectively. Note that the regressions are forced through the origin (intercept is zero); thus, the individual-specific mean is fixed to be 0 .

The parameters of the above models are estimated iteratively and depend on one another allowing the test of our main predictions in a single statistical framework (see graphical 
representation of the whole model structure in electronic supplementary material). Such inferences typically require Bayesian approaches based on Markov chain Monte Carlo (MCMC) processes (Gelman et al. 2004). For this purpose, we applied procedures available in program JAGS (Plummer 2003) which we controlled from within the R statistical environment (R Developmental Core Team 2018) using the package rjags (Plummer 2014). For each model, we defined three MCMC chains from different starting values and with 10,000 iterations of burn in period before sampling the posterior distribution. The posterior sample relied on the subsequent 100,000 iterations that were combined across chains. Before interpreting the results, we applied the conventional model diagnostic procedures for each chain to verify convergence and the lack of autocorrelation (Gelman et al. 2004). Bayesian methods require priors to be defined for each parameter estimated. We set these values to have a minimal influence on the posterior distribution, as we had no previous knowledge about them (uninformative, flat priors). The means of the posterior distributions were used for further interpretation by also considering the associated $95 \%$ credible intervals $(95 \% \mathrm{CrI})$. If the generated $95 \% \mathrm{CrI}$ of the posterior distribution for a parameter did not include zero, the parameter was considered to have a significant effect. Model codes are available in the electronic supplementary material.

\section{Results}

Our models suggest the directional effect of time across the experiment $\left(\beta_{2}=0.165,95 \% \mathrm{CrI}=[0.034,0.297]\right)$ : individuals became slightly risk-averse as time progresses (Fig. 1). In addition, Wolbachia-infected individuals were more fearful than parasite-free conspecifics $\left(\beta_{5}=0.647[0.144,1.156]\right)$. Risk-taking had an individual- (random intercept: $\sigma_{\text {ind }}^{2}=$ $0.454[0.328,0.636])$ and day-specific (random intercept: $\left.\sigma_{d a y_{0}}^{2}=0.121[0.09,0.216]\right)$ expression. Pill bugs substantially differed in environmentally induced behavioural plasticity (random slope: $\sigma_{\text {ind }}^{2}=0.176$ [0.065, 0.191]; Fig. 2a) and time-induced habituation (random slope: $\sigma_{i n d_{2}}^{2}=0.146$ [0.114, 0.262]; Fig. 2b). For remaining non-significant effects, see Table 1.

We found that individuals displayed decreased residual variation across time $\left(\gamma_{2}=-0.089\right.$ [ $\left.-0.165,-0.012\right]$; Fig. 3$)$. Also, the level of residual variation was affected by the environment: pill bugs' behaviour was less predictable (i.e. high residual variation) in the unfamiliar, than in the familiar environment $\left(\gamma_{1}=0.074[0.034,0.115]\right)$. There was a substantial among-individual (random intercept: $\sigma_{\text {oind }}^{2}=0.267[0.185$, $0.383]$ ) and across day (random intercept: $\sigma_{\sigma d a y}^{2}=0.176$

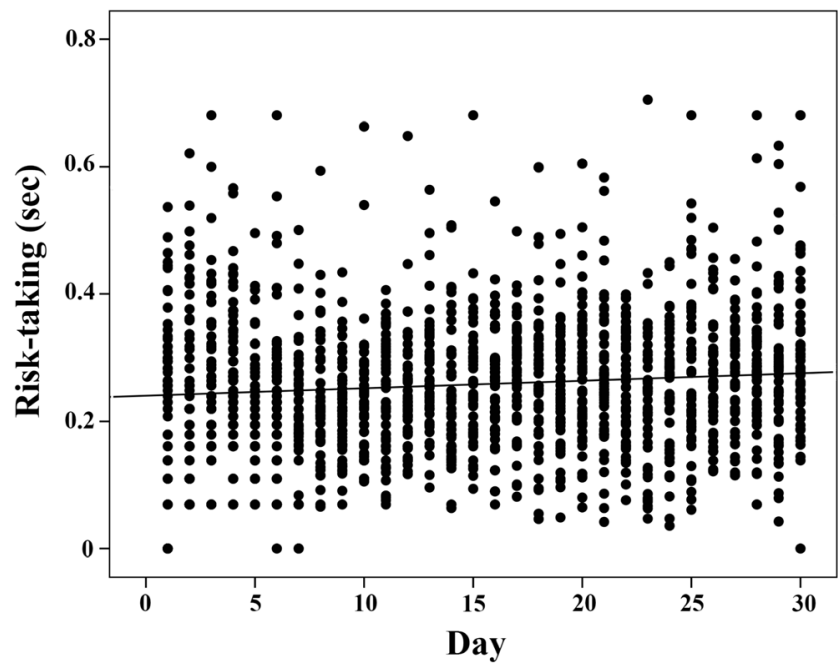

Fig. 1 Differences in risk-taking over time (habituation) in common pill bug (Armadillidium vulgare). Note that risk-taking is a latency variable, i.e. lower values represent higher risk-taking

$[0.116,0.254])$ variation in residual within-individual variation. For remaining non-significant effects, see Table 1.

None of the fixed effects affected individual-specific behavioural plasticity (Table 1); on the other hand, habituation was stronger in females $\left(\varphi_{1}=-0.230[-0.428\right.$, $0.030])$ and in larger individuals $\left(\varphi_{2}=0.110[0.015\right.$, 0.206]; Fig. 4; Table 1).

\section{Discussion}

Here, we demonstrated substantial differences in risk-taking of $A$. vulgare at several hierarchical level of behavioural variation. Pill bugs showed significant between-individual differences not just in mean risk-taking (i.e. among-individual variation), but in the degree to which they adjust their behaviour to previous environmental conditions (i.e. behavioural plasticity), and how consistently express their behaviour in any given environment (i.e. residual variation). These patterns add to prior studies indicating that both behavioural plasticity and residual variation can be seen as potentially independent components of animal behavioural variation (Dingemanse et al. 2010; Stamps et al. 2012; Biro and Adriaenssens 2013; Briffa 2013; Briffa et al. 2013; Dingemanse and Wolf 2013; Stamps 2016; Chang et al. 2017; Guayasamin et al. 2017; Lichtenstein et al. 2017). Further, in line with several prior studies, we found that individual variation in residual variation was influenced by individual state or environmental differences (Briffa 2013; Bridger et al. 2015; Westneat et al. 2015). Our results provide empirical support to the notion that inter-individual differences in within-individual behavioural variation may be the outcome of adaptive processes rather than reflecting non-functional variation (Biro and Adriaenssens 2013). Here, we discuss how these effects on 


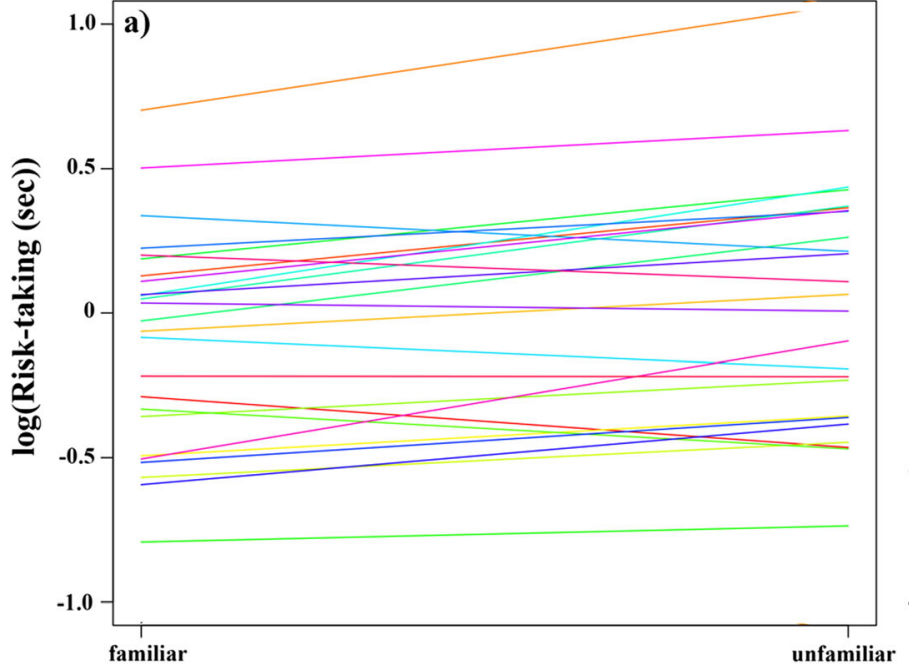

Environment

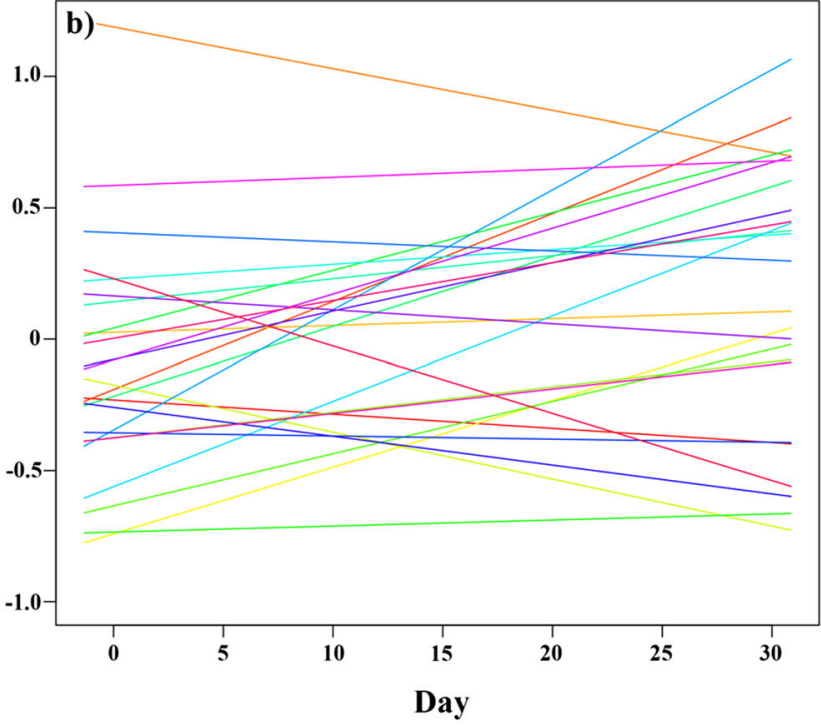

Day

Fig. 2 Individual behavioural reaction norms across a time (sensitization) and $\mathbf{b}$ environments in common pill bug (Armadillidium vulgare). Note that risk-taking is a latency variable, i.e. lower values represent higher risk-taking

among-individual variation, residual variation and behavioural plasticity fit to the existing theories.

\section{Among-individual variation}

A. vulgare individuals infected with Wolbachia took less risk than their uninfected conspecifics. It has been suggested that infection with mild effects on the hosts' fitness is coupled with higher rates of behavioural activity, as infection often increases energetic needs (Lafferty and Morris 1996; GarcíaLongoria et al. 2014; Gyuris et al. 2016). On the other hand, parasites with severe negative effects on their hosts' fitness are more likely to reduce behavioural activity, due to heavily reduced state (e.g. low body condition; Ferguson et al. 2011; Hammond-Tooke et al. 2012; Poulin 2013), which may eventuate the emergence of individual behavioural strategies in order to cope with these disadvantages (Barber and Dingemanse 2010; Kortet et al. 2010; Horváth et al. 2016).

Pathological effects of Wolbachia infection are rarely studied; however, it is known that the parasite is able to avoid or even manipulate the host's immune system and affect senescence processes directly (Braquart-Varnier et al. 2008; Le Clec'h et al. 2012). In A. vulgare, different strains have differently severe effects on the host. For instance, $w$ VulC is a widespread and invasive feminizing strain, inducing low haemocyte level and intense septicemia, reducing the host lifespan considerably (Braquart-Varnier et al. 2008; Sicard et al. 2010; Chevalier et al. 2011; Le Clec'h et al. 2012, 2013). On the other hand, wDil has no proven direct effects on A. vulgare fitness, but does induce cytoplasmic incompatibility which may generate indirect costs (Sicard et al. 2010; Valette et al. 2013). Here, lowered risk-taking in infected pill bugs could be a result of compensation for lowered body condition and physiological performance. However, considering the low prevalence of Wolbachia infection in or sample, this finding should be interpreted with caution (Bell et al. 2010). Thus, our conclusions regarding strength and true mechanisms behind this pattern here are rather tentative. Nevertheless, we believe that this finding at least warrants more targeted research on the potential effect of Wolbachia infection on hosts' behaviour.

\section{Residual variation}

Residual variation in behaviour was found to decrease across days, in correspondence with human psychology literature as well as observations on various vertebrate and invertebrate taxa showing residual variation decreasing with increasing experience (Stamps et al. 2012; Stamps and Krishnan 2014). On the contrary, in a recent study performed on guppies (Poecilia reticulata), Mitchell et al. (2016) report no change in residual variation across a timespan similar to ours. It is known that adult individuals may acclimate by their novel environment quicker and express lower residual variability within shorter periods (Biro 2012); nevertheless, ontogenetic effects are rather implausible in our case. A more likely possibility is that residual variation in risk-taking decreased due to continued acclimation to our experimental procedure (Biro and Adriaenssens 2013; Mitchell et al. 2016).

Pill bugs express significantly higher residual variation in the unfamiliar than in the familiar environment. This finding is consistent with recent reports from both vertebrate and invertebrate taxa (Dingemanse et al. 2010; Stamps et al. 2012; Briffa 2013; Nakayama et al. 2016), suggesting that potentially risky environments decrease predictability of behaviour (but see Urszán et al. 2018). Thus, high residual variation 
Table 1 Sources of variation in risk-taking of common pill bug (Armadillidium vulgare). Estimates were derived from a double hierarchical general linear model

Model Posterior mean $(95 \% \mathrm{CrI})$

(a)

Mean
Intercept
Environment
Day
Sex
Size
Wolbachia
Order
Individual (random intercept)
Day (random intercept)
Individual $\times$ environment (random slope)
Individual $\times$ day (random slope)

(b)

Residual variation

Intercept

Environment

$\beta$

$-0.001(-0.272,0.271)$

$0.075(-0.015,0.165)$

$0.165(0.034,0.297)$

$-0.319(-0.770,0.125)$

$0.105(-0.110,0.321)$

$0.647(0.144,1.156)$

$-0.019(-0.056,0.018)$

$\sigma^{2}$

$0.454(0.328,0.636)$

$0.121(0.09,0.216)$

$0.176(0.065,0.191)$

$0.146(0.114,0.262)$

$-0.319(-0.494,-0.145)$

$0.074(0.034,0.115)$

$-0.089(-0.165,-0.012)$

$-0.039(-0.320,0.242)$

$0.065(-0.069,0.197)$

$0.270(-0.040,0.581)$

$-0.024(-0.065,0.017)$

$\sigma^{2}$

Individual (random intercept)

$0.267(0.185,0.383)$

Day (random intercept)

$0.176(0.116,0.254)$

(c)

Behavioural plasticity

Sex

Size

Wolbachia

$\delta$

$-0.023(-0.173,0.128)$

$-0.013(-0.085,0.06)$

$-0.008(-0.188,0.171)$

(d)

Sensitization

Sex

Size

Wolbachia

$\varphi$

$-0.230(-0.428,-0.030)$

$0.110(0.015,0.206)$

$0.120(-0.112,0.350)$

Day (day of behavioural trial), order (order of familiar vs. unfamiliar environments during behavioural testing), sex (factor with two levels: male vs. female), body size and Wolbachia infection (factor with two levels: infected vs. uninfected) were fitted as fixed effects without interactions. Posterior means and 95\% credible intervals (CrI) are shown. Effects strongly supported by the model (95\% CI not overlapping) are in italic font. Effects on (a) means, (b) the residual variation (c) variance in individual plasticity and (d) variance in individual sensitization

could be seen as an antipredator response (Biro and Adriaenssens 2013; Briffa et al. 2013). Predation pressure substantially affects behavioural actions of individuals in

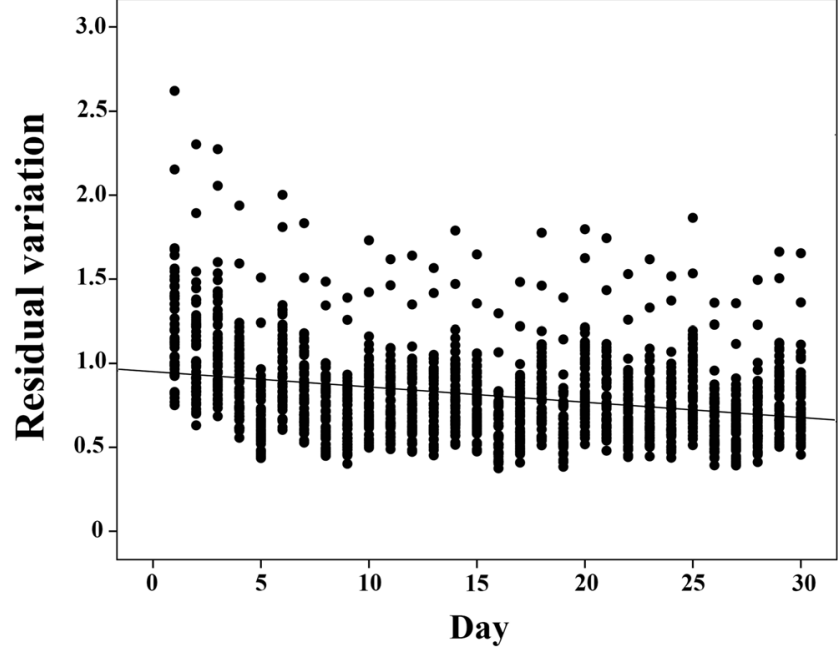

Fig. 3 Differences in risk-taking residual variation over time in common pill bug (Armadillidium vulgare). Estimates were obtained from the statistical model (see Table 1)

order to avoid potentially risky encounters (Bell and Sih 2007; Kortet et al. 2010; Luttbeg and Sih 2010; Engqvist et al. 2015; Sih et al. 2015). However, taking that substantial differences in residual variation were present irrespective of environmental factors, other most likely internal factors should also affect residual variation (Sih et al. 2004, 2015; Briffa 2013; Bierbach et al. 2017). Again, we cannot be sure regarding exact background mechanisms of this pattern. It is known that in A. vulgare, mating is linked to moulting cycle, during which individuals are more vulnerable to predators (Beauché and Richard 2013). It is likely that high residual variation in emergence from conglobation during the reproductive season helps secure survival and thus future reproductive success of the individuals.

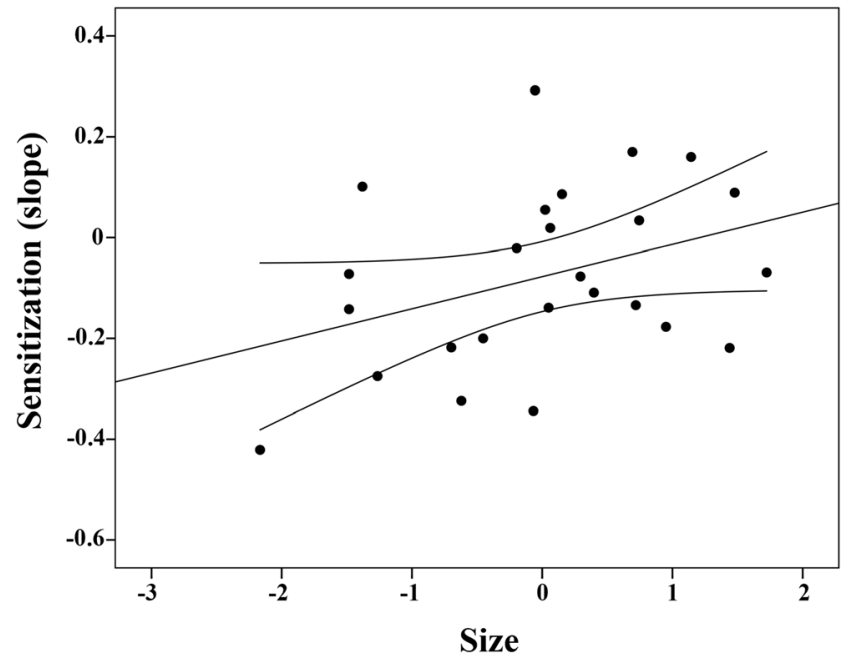

Fig. 4 Association between behavioural plasticity of risk-taking over time (sensitization) and size in common pill bug (Armadillidium vulgare). Individual sensitization is represented by the slope of the individual behavioural reaction norm in response to time 


\section{Behavioural plasticity}

We found significant decrease of risk-taking with time. As habituation is assumed to reduce unnecessary antipredator responses (i.e. length of conglobation) (Rodríguez-Prieto et al. 2010, 2011; Vincze et al. 2016), our pattern rather suggests a reverse response that is known as sensitization; an internal mechanism intensifies behavioural response to constant stimulation (Bee 2001; Martin and Réale 2008; Stamps et al. 2012; Osborn and Briffa 2017). Theory predicts that sensitization eventually will fade and habituation becomes the main pattern of behavioural change over time, but empirical studies provide limited support for this (Bee 2001; Osborn and Briffa 2017). Our data indicate no sign of habituation (i.e. lowered risktaking) during 30 days of experiment in either the familiar or in the unfamiliar environment. High level of sensitization is assumed to be linked to high stimulus rate and intensity (Bee 2001), and since our assays were conducted mostly on a daily basis, the result is somewhat in line with this prediction.

Individual-specific behavioural plasticity was not affected by individual state. On the other hand, among-individual variance in slope was influenced by sex and size, i.e. females and larger specimens (irrespective of sex) became shier with time. Empirical data suggest that individual-specific differences in behavioural plasticity are the outcome of variability of inherently stable or labile state variables (Luttbeg and Sih 2010; Wolf and Weissing 2010; Mathot and Dingemanse 2014; Araya-Ajoy and Dingemanse 2017; Mitchell and Biro 2017). However, based on current correlative data, we cannot reconstruct the exact biological mechanism in the background of this pattern, especially if we take into account that differences in state are affected by both genetic and environmental variation (Mathot and Dingemanse 2014). The most plausible explanation is that high behavioural plasticity likely secures future reproductive success of females and large pill bugs. In general, the patterns reported in this subsection have also added to the growing number of data indicating that despite behaving in a consistent way, individuals still maintain the capability to adjust their behaviour to changing environmental conditions (i.e. being behaviourally plastic) (DeWitt et al. 1998; Dingemanse and Wolf 2013; Mathot and Dingemanse 2014).

\section{Conclusions}

Taken together, we found components of behavioural variation (intercept, slope and residuals) to exhibit amongindividual variation and to be sensitive to different variables related to individual state. These results suggest that all three components are integral parts of an individual's behavioural strategy and that individuals are indeed plastic upon environmental challenge and within-population behavioural variation can be at least partly explained by variation in fixed and labile state variables. We recommend studying behavioural variation in an integrative approach and along longer observational periods, as animal personality sensu lato, or in other words, individual behavioural strategy seems to be indeed more than just variation in mean behaviour.

Acknowledgements Open access funding provided by Eötvös Loránd University (ELTE). Our sincere thanks go to David Westneat for his valuable comments and advices on statistical methods which helped us highly improve our manuscript. We are also grateful for two anonymous reviewers for their helpful comments. We thank Joel Almeida, Natalia Peixoto Henriques, Antonio Scaruda and Tamara Vieira for their help during the collection and the experiments. Help provided by Erzsébet Hornung in species identification and sexing is much respected. In addition, we thank technical assistance of Valéria Mester in the molecular work. This work was supported by the Hungarian State PhD Scholarship (for GeH, TJU and GB), the Hungarian Scientific Research Fund (OTKA-K 105517 for GH and OTKA-K 109223 for JB) and the János Bolyai Scholarship of the Hungarian Academy of Sciences (for GH and JB). GeH, GH and BG were also supported by the National Research, Development and Innovation Fund for international cooperation (SNN 125627). LZG was supported by funds from the Ministry of Economy and Competitiveness in Spain (CGL2015-70639-P) and the National Research, Development and Innovation Office in Hungary (K 115970; K 129215).

\section{Compliance with ethical standards}

Conflict of interest The authors declare that they have no conflict of interest.

Ethical approval Experiments were performed according to the guidelines of the Hungarian Act of Animal Care and Experimentation (1998, XXVIII, section 243/1998), which conforms to the regulation of animal experiments by the European Union.

Open Access This article is distributed under the terms of the Creative Commons Attribution 4.0 International License (http:// creativecommons.org/licenses/by/4.0/), which permits unrestricted use, distribution, and reproduction in any medium, provided you give appropriate credit to the original author(s) and the source, provide a link to the Creative Commons license, and indicate if changes were made.

Publisher's note Springer Nature remains neutral with regard to jurisdictional claims in published maps and institutional affiliations.

\section{References}

Araya-Ajoy YG, Dingemanse NJ (2017) Repeatability, heritability, and age-dependence in the aggressiveness reaction norms of a wild passerine bird. J Anim Ecol 86:227-238. https://doi.org/10.1111/13652656.12621

Barber I, Dingemanse NJ (2010) Parasitism and the evolutionary ecology of animal personality. Philos Trans R Soc Lond Ser B Biol Sci 365: 4077-4088. https://doi.org/10.1098/rstb.2010.0182

Bates D, Mächler M, Bolker B, Walker S (2015) Fitting linear mixedeffects models using lme4. J Stat Softw 67:1-48. https://doi.org/10. 18637/jss.v067.i01 
Beauché F, Richard F (2013) The best timing of mate search in Armadillidium vulgare (Isopoda, Oniscidea). PLoS One 8:e57737. https://doi.org/10.1371/journal.pone.0057737

Beckmann C, Biro P (2013) On the validity of a single (boldness) assay in personality research. Ethology 119:937-947. https://doi.org/10. 1111/eth.12137

Bee M (2001) Habituation and sensitization of aggression in bullfrogs (Rana catesbeiana): testing the dual-process theory of habituation. J Comp Psychol 115:307-316. https://doi.org/10.1037/0735-7036. 115.3.307

Bell AM, Sih A (2007) Exposure to predation generates personality in threespined sticklebacks (Gasterosteus aculeatus). Ecol Lett 10:828834. https://doi.org/10.1111/j.1461-0248.2007.01081.x

Bell AM, Hankison SJ, Laskowski KL (2009) The repeatability of behaviour: a meta-analysis. Anim Behav 77:771-783. https://doi.org/ 10.1016/j.anbehav.2008.12.022

Bell B, Morgan GB, Schoeneberger J et al (2010, 2010) Dancing the sample-size limbo with mixed models: how low can you go? SAS Glob Forum:1-11

Bierbach D, Laskowski KL, Wolf M (2017) Behavioural individuality in clonal fish arises despite near-identical rearing conditions. Nat Commun 8:15361. https://doi.org/10.1038/ncomms15361

Biro PA (2012) Do rapid assays predict repeatability in labile (behavioural) traits? Anim Behav 83:1295-1300. https://doi.org/ 10.1016/j.anbehav.2012.01.036

Biro PA, Adriaenssens B (2013) Predictability as a personality trait: consistent differences in intraindividual behavioral variation. Am Nat 182:621-629. https://doi.org/10.1086/673213

Biro PA, Beckmann C, Stamps JA (2010) Small within-day increases in temperature affects boldness and alters personality in coral reef fish. Proc Biol Sci 277:71-77. https://doi.org/10.1098/rspb.2009.1346

Braquart-Varnier C, Lachat M, Herbinière J, Johnson M, Caubet Y, Bouchon D, Sicard M (2008) Wolbachia mediate variation of host immunocompetence. PLoS One 3:e3286. https://doi.org/10.1371/ journal.pone. 0003286

Bridger D, Bonner SJ, Briffa M, Briffa M (2015) Individual quality and personality : bolder males are less fecund in the hermit crab Pagurus bernhardus. Proc R Soc B Biol Sci 282:20142492

Briffa M (2013) Plastic proteans: reduced predictability in the face of predation risk in hermit crabs. Biol Lett 9:20130592. https://doi. org/10.1098/rsbl.2013.0592

Briffa M, Bridger D, Biro P (2013) How does temperature affect behaviour? Multilevel analysis of plasticity, personality and predictability in hermit crabs. Anim Behav 86:47-54. https://doi.org/10.1016/j. anbehav.2013.04.009

Carter AJ, Marshall HH, Heinsohn R, Cowlishaw G (2012) How not to measure boldness: novel object and antipredator responses are not the same in wild baboons. Anim Behav 84:603-609. https://doi.org/ 10.1016/j.anbehav.2012.06.015

Chang CC, Teo HY, Norma-Rashid Y, Li D (2017) Predator personality and prey behavioural predictability jointly determine foraging performance. Sci Rep 7:1-8. https://doi.org/10.1038/srep40734

Chevalier F, Herbiniere-Gaboreau J, Bertaux J et al (2011) The immune cellular effectors of terrestrial isopod armadillidium vulgare: meeting with their invaders, wolbachia. PLoS One 6:e18531. https://doi. org/10.1371/journal.pone.0018531

Cleasby IR, Nakagawa S, Schielzeth H (2015) Quantifying the predictability of behaviour: statistical approaches for the study of betweenindividual variation in the within-individual variance. Methods Ecol Evol 6:27-37. https://doi.org/10.1111/2041-210X.12281

DeWitt TJ, Sih A, Wilson DS (1998) Cost and limits of phenotypic plasticity. Trends Ecol Evol 13:77-81. https://doi.org/10.1111/j. 1558-5646.2009.00647.x

Dingemanse NJ, Wolf M (2013) Between-individual differences in behavioural plasticity within populations: causes and consequences.
Anim Behav 85:1031-1039. https://doi.org/10.1016/j.anbehav. 2012.12.032

Dingemanse NJ, Kazem AJN, Réale D, Wright J (2010) Behavioural reaction norms: animal personality meets individual plasticity. Trends Ecol Evol 25:81-89. https://doi.org/ 10.1016/j.tree.2009.07.013

DiRienzo N, Niemelä PT, Skog A et al (2015) Juvenile pathogen exposure affects the presence of personality in adult field crickets. Front Ecol Evol 3:1-10. https://doi.org/10.3389/fevo.2015.00036

DiRienzo N, Niemelä PT, Hedrick AV, Kortet R (2016) Adult bacterial exposure increases behavioral variation and drives higher repeatability in field crickets. Behav Ecol Sociobiol 70:1941-1947. https:// doi.org/10.1007/s00265-016-2200-5

Engqvist L, Cordes N, Reinhold K (2015) Evolution of risk-taking during conspicuous mating displays. Evolution (N Y) 69:395-406. https:// doi.org/10.1111/evo.12591

Ferguson JA, Koketsu W, Ninomiya I, Rossignol PA, Jacobson KC, Kent ML (2011) Mortality of coho salmon (Oncorhynchus kisutch) associated with burdens of multiple parasite species. Int J Parasitol 41: 1197-1205. https://doi.org/10.1016/j.ijpara.2011.07.005

Fleury F, Vavre F, Ris N et al (2000) Physiological cost induced by the maternally-transmitted endosymbiont Wolbachia in the Drosophila parasitoid Leptopilina heterotoma. Parasitology 121(Pt 5):493-500. https://oi.org/10.1017/S0031182099006599

Garamszegi LZ, Herczeg G (2012) Behavioural syndromes, syndrome deviation and the within- and between-individual components of phenotypic correlations: when reality does not meet statistics. Behav Ecol Sociobiol 66:1651-1658. https://doi.org/10.1007/ s00265-012-1439-8

Garamszegi LZ, Markó G, Herczeg G (2012) A meta-analysis of correlated behaviours with implications for behavioural syndromes: mean effect size, publication bias, phylogenetic effects and the role of mediator variables. Evol Ecol 26:1213-1235. https://doi.org/10. 1007/s10682-012-9589-8

García-Longoria L, Garamszegi LZ, Moøller P (2014) Host escape behavior and blood parasite infections in birds. Behav Ecol 25:890 900. https://doi.org/10.1093/beheco/aru066

Gelman A, Carlin JB, Stern HS, Rubin DB (2004) Bayesian data analysis, 2nd edn. Chapman \& Hall/CRC Press, Boca Raton

Guayasamin OL, Couzin ID, Miller NY (2017) Behavioural plasticity across social contexts is regulated by the directionality of interindividual differences. Behav Process 141:196-204. https://doi. org/10.1016/j.beproc.2016.10.004

Gyuris E, Hankó JF, Feró O, Barta Z (2016) Personality and ectoparasitic mites (Hemipteroseius adleri) in firebugs (Pyrrhocoris apterus). Behav Process 122:67-74. https://doi.org/10.1016/j.beproc.2015. 11.011

Hammond-Tooke C, Nakagawa S, Poulin R (2012) Parasitism and behavioural syndromes in the fish Gobiomorphus cotidianus. Behaviour 149:601-622. https://doi.org/10.1163/ 156853912 X648903

Hilgenboecker K, Hammerstein P, Schlattmann P, Telschow A, Werren JH (2008) How many species are infected with Wolbachia? - a statistical analysis of current data. FEMS Microbiol Lett 281:215-220. https://doi.org/10.1111/j.1574-6968.2008.01110.x

Horváth G, Martín J, López P, Garamszegi LZ, Bertók P, Herczeg G (2016) Blood parasite infection intensity covaries with risk-taking personality in male Carpetan rock lizards (Iberolacerta cyreni). Ethology 122:355-363. https://doi.org/ 10.1111/eth. 12475

Horváth G, Martín J, López P, Garamszegi LZ, Herczeg G (2017) Food and vitamin D3 availability affects lizard personalities: an experiment. Behav Ecol Sociobiol 71:27. https://doi.org/10.1007/s00265016-2257-1 
Hugie DM (2003) The waiting game: a "battle of waits" between predator and prey. Behav Ecol 14:807-817. https://doi.org/10.1093/beheco/ $\arg 054$

Humphries DA, Driver PM (1970) Protean defence by prey animals. Oecologia 5:285-302

Jones KA, Jackson AL, Ruxton GD (2011) Prey jitters; protean behaviour in grouped prey. Behav Ecol 22:831-836. https://doi.org/10.1093/ beheco/arr062

Kortet R, Hedrick AV, Vainikka A (2010) Parasitism, predation and the evolution of animal personalities. Ecol Lett 13:1449-1458. https:// doi.org/10.1111/j.1461-0248.2010.01536.x

Kralj-Fišer S, Schneider JM (2012) Individual behavioural consistency and plasticity in an urban spider. Anim Behav 84:197-204. https:// doi.org/10.1016/j.anbehav.2012.04.032

Lafferty KD, Morris AK (1996) Altered baheviour of parasitized killifish encreases susceptibility to predation by birds final hosts. Ecology 77:1390-1397. https://doi.org/10.2307/2265536

Le Clec'h W, Braquart-Varnier C, Raimond M et al (2012) High virulence of Wolbachia after host switching: when autophagy hurts. PLoS Pathog 8:e1002844. https://doi.org/10.1371/journal.ppat.1002844

Le Clec'h W, Raimond M, Guillot S et al (2013) Horizontal transfers of feminizing versus non-feminizing Wolbachia strains: from harmless passengers to pathogens. Environ Microbiol 15:2922-2936. https:// doi.org/10.1111/1462-2920.12172

Lee Y, Nelder JA (1996) Hierarchical generalized linear models. J R Stat Soc Ser B Appl Stat 58:619-678

Lee Y, Nelder J (2006) Double hierarchical generalized linear modelsdiscussion. J R Stat Soc Ser C Appl Stat 55:139-185. https://doi.org/ 10.1111/j.1467-9876.2006.00538.x

Lichtenstein JLL, DiRienzo N, Knutson K, Kuo C, Zhao KC, Brittingham HA, Geary SE, Ministero S, Rice HK, David Z, Scharf I, Pruitt JN (2016) Prolonged food restriction decreases body condition and reduces repeatability in personality traits in webbuilding spiders. Behav Ecol Sociobiol 70:1793-1803. https://doi. org/10.1007/s00265-016-2184-1

Lichtenstein JLL, Chism GT, Kamath A, Pruitt JN (2017) Intraindividual behavioral variability predicts foraging outcome in a beach-dwelling jumping spider. Sci Rep 7:18063. https://doi.org/10.1038/s41598$017-18359-\mathrm{x}$

Luttbeg B, Sih A (2010) Risk, resources and state-dependent adaptive behavioural syndromes. Philos Trans R Soc Lond Ser B Biol Sci 365:3977-3990. https://doi.org/10.1098/rstb.2010.0207

Martin JGA, Réale D (2008) Temperament, risk assessment and habituation to novelty in eastern chipmunks, Tamias striatus. Anim Behav 75:309-318. https://doi.org/10.1016/j.anbehav.2007.05.026

Mathot KJ, Dingemanse NJ (2014) Plasticity and personality. In: Martin LB, Ghalambor, Cameron K, Woods A (eds) Integrative Organismal Biology. John Wiley \& Sons, Inc, Hoboken, pp 55-69

Matsuno H, Moriyama T (2012) Behavioral evidence for internal factors affecting duration of conglobation in pill bugs (Armadillidium vulgare, Isopoda, Crustacea). Acta Biol Hung 63:80-82. https:// doi.org/10.1556/ABiol.63.2012.Suppl.2.9

Ming Q-L, Shen J-F, Cheng C, Liu CM, Feng ZJ (2015) Wolbachia infection dynamics in Tribolium confusum (Coleoptera: Tenebrionidae) and their effects on host mating behavior and reproduction. J Econ Entomol 108:1408-1415. https://doi.org/10.1093/ jee/tov053

Mitchell D, Biro PA (2017) Is behavioral plasticity consistent across different environmental gradients and through time. Proc B 284:1-8

Mitchell DJ, Fanson BG, Beckmann C, Biro PA (2016) Towards powerful experimental and statistical approaches to study intraindividual variability in labile traits. R Soc Open Sci 3:160352. https://doi.org/ 10.1098/rsos.160352

Moreau J, Bertin A, Caubet Y, Rigaud T (2001) Sexual selection in an isopod with Wolbachia-induced sex reversal: males prefer real females. J Evol Biol 14:388-394. https://doi.org/10.1046/j.14209101.2001.00292.x

Nakayama S, Laskowski KL, Klefoth T, Arlinghaus R (2016) Betweenand within-individual variation in activity increases with water temperature in wild perch. Behav Ecol 27:1676-1683. https://doi.org/ 10.1093/beheco/arw090

Niemelä PT, Vainikka A, Forsman JT, Loukola OJ, Kortet R (2013) How does variation in the environment and individual cognition explain the existence of consistent behavioral differences? Ecol Evol 3:457464. https://doi.org/10.1002/ece3.451

Osborn A, Briffa M (2017) Does repeatable behaviour in the laboratory represent behaviour under natural conditions? A formal comparison in sea anemones. Anim Behav 123:197-206. https://doi.org/10. 1016/j.anbehav.2016.10.036

Plummer M (2003) JAGS: A program for analysis of Bayesian graphical models using Gibbs sampling. Proc 3rd Int Work Distrib Stat Comput (DSC 2003) 20-22

Plummer M (2014) rjags: Bayesian graphical models using MCMC

Poulin R (2013) Parasite manipulation of host personality and behavioural syndromes. J Exp Biol 216:18-26. https://doi.org/10.1242/jeb. 073353

R Developmental Core Team (2018) R: A language and environment for statistical computing

Richardson G, Dickinson P, Burman OHP, Pike TW (2018) Unpredictable movement as an anti-predator strategy. Proceedings of the Royal Society B: Biological Sciences 285(1885):20181112. https://doi.org/10.1098/rspb.2018.1112

Rodríguez-Prieto I, Martín J, Fernández-Juricic E (2010) Habituation to low-risk predators improves body condition in lizards. Behav Ecol Sociobiol 64:1937-1945. https://doi.org/10.1007/s00265-0101004-2

Rodríguez-Prieto I, Martín J, Fernández-Juricic E (2011) Individual variation in behavioural plasticity: direct and indirect effects of boldness, exploration and sociability on habituation to predators in lizards. Proc Biol Sci 278:266-273. https://doi.org/10.1098/rspb.2010. 1194

Sicard M, Chevalier F, De Vlechouver M et al (2010) Variations of immune parameters in terrestrial isopods: a matter of gender, aging and Wolbachia. Naturwissenschaften 97:819-826. https://doi.org/10. 1007/s00114-010-0699-2

Sih A, Bell AM, Johnson JC, Ziemba RE (2004) Behavioural syndromes: an integrative overview. Q Rev Biol 79:241-277. https://doi.org/10. $1086 / 516403$

Sih A, Mathot KJ, Moirón M, Montiglio PO, Wolf M, Dingemanse NJ (2015) Animal personality and state- behaviour feedbacks : a review and guide for empiricists. Trends Ecol Evol 30:50-60. https:// doi.org/10.1016/j.tree.2014.11.004

Stamps JA (2016) Individual differences in behavioural plasticities. Biol Rev 91:534-567. https://doi.org/10.1111/brv.12186

Stamps JA, Krishnan VV (2014) Combining information from ancestors and personal experiences to predict individual differences in developmental trajectories. Am Nat 184:647-657. https://doi.org/10. 1086/678116

Stamps JA, Briffa M, Biro PA (2012) Unpredictable animals: individual differences in intraindividual variability (IIV). Anim Behav 83: 1325-1334. https://doi.org/10.1016/j.anbehav.2012.02.017

Tuf IH, Drábková L, Šipoš J (2015) Personality affects defensive behaviour of Porcellio scaber (Isopoda, Oniscidea). Zookeys 515:159171. https://doi.org/10.3897/zookeys.515.9429

Urszán T, Garamszegi L, Nagy G et al (2018) Experience during development triggers between-individual variation in behavioural plasticity. J Anim Ecol 87:1264-1273. https://doi.org/10.1111/1365-2656. 12847

Vala F, Egas M, Breeuwer JAJ, Sabelis MW (2004) Wolbachia affects oviposition and mating behaviour of its spider mite host. J Evol Biol 17:692-700. https://doi.org/10.1046/j.1420-9101.2003.00679.x 
Valette V, Bitome Essono PY, Le Clec'h W et al (2013) Multi-infections of feminizing Wolbachia strains in natural populations of the terrestrial isopod Armadillidium Vulgare. PLoS One 8:e82633. https:// doi.org/10.1371/journal.pone.0082633

Velasque M, Briffa M (2016) The opposite effects of routine metabolic rate and metabolic rate during startle responses on variation in the predictability of behaviour in hermit crabs. Behaviour 153:15451566. https://doi.org/10.1163/1568539X-00003371

Vincze E, Papp S, Preiszner B, Seress G, Bókony V, Liker A (2016) Habituation to human disturbance is faster in urban than rural house sparrows. Behav Ecol 27:1304-1313. https://doi.org/10.1093/ beheco/arw047

Werren JH, Windsor DM (2000) Wolbachia infection frequencies in insects: evidence of a global equilibrium? Proc Biol Sci 267:12771285. https://doi.org/10.1098/rspb.2000.1139

Werren JH, Baldo L, Clark ME (2008) Wolbachia: master manipulators of invertebrate biology. Nat Rev Microbiol 6:741-751. https://doi. org/10.1038/nrmicro1969

West-Eberhard MJ (2003) Developmental plasticity and evolution, 1st edn. Oxford University Press, New York
Westneat DF, Hatch MI, Wetzel DP, Ensminger AL (2011) Individual variation in parental care reaction norms: integration of personality and plasticity. Am Nat 178:652-667. https://doi.org/10.1086/662173

Westneat DF, Schofield M, Wright J (2013) Parental behavior exhibits among-individual variance, plasticity, and heterogeneous residual variance. Behav Ecol 24:598-604. https://doi.org/10.1093/beheco/ $\operatorname{ars} 207$

Westneat DF, Wright J, Dingemanse NJ (2015) The biology hidden inside residual within-individual phenotypic variation. Biol Rev 90:729 743. https://doi.org/10.1111/brv.12131

Wolf M, Weissing FJ (2010) An explanatory framework for adaptive personality differences. Philos Trans R Soc Lond Ser B Biol Sci 365:3959-3968. https://doi.org/10.1098/rstb.2010.0215

Zhao DX, Zhang XF, Chen DS, Zhang YK, Hong XY (2013) Wolbachiahost interactions: host mating patterns affect Wolbachia density dynamics. PLoS One 8:e66373. https://doi.org/10.1371/journal.pone. 0066373

\section{Affiliations}

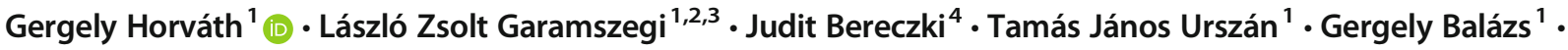 Gábor Herczeg ${ }^{1}$}

1 Behavioural Ecology Group, Department of Systematic Zoology and Ecology, Eötvös Loránd University, Pázmány Péter Sétány 1/c, Budapest H-1117, Hungary Department of Evolutionary Ecology, Estación Biológica de Donaña-CSIC, c/ Americo Vespucio, 26, 41092 Seville, Spain

3 MTA-ELTE, Theoretical Biology and Evolutionary Ecology Research Group, Department of Plant Systematics, Ecology and
Theoretical Biology, Eötvös Loránd University, Pázmány Péter Sétány 1/c, Budapest H-1117, Hungary

4 Department of Evolutionary Zoology and Human Biology, Institute of Biology and Ecology, University of Debrecen, Egyetem tér 1, Debrecen H-4032, Hungary 